\title{
CPD QUESTIONS
}

\section{Journal 38}

\section{Two CPD points are awarded for the correct completion and submission of the questions below.}

CPD questionnaires must be completed online via www.cpdjournals.org.za.

After submission you can check the answers and print your certificate.

Questions may be answered up to 6 months after publication of each issue.

This programme is available free of charge to members of the HIV Clinicians Society and SAMA only.

1. True $(A)$ or false $(B)$ - click on the correct answer: The immune reconstitution syndrome (IRIS) typically occurs late in antiretroviral therapy.

2. True (A) or false (B) - click on the correct answer: IRIS is a typical manifestation of antiretroviral therapy (ART) commencement in early HIV infection in pregnant women.

3. True (A) or false (B) - click on the correct answer: Cryptococcal meningitis is a serious IRIS manifestation.

4. True $(A)$ or false $(B)$ - click on the correct answer: In regions where highly active antiretroviral therapy is offered in pregnancy regardless of maternal CD4 count, vertical HIV transmission has almost disappeared.

5. True $(A)$ or false $(B)$ - click on the correct answer: TB colitis may be an extrapulmonary complication of HIV/ TB co-infection.

6. True $(A)$ or false $(B)$ - click on the correct answer: Abdominal ultrasound is a useful investigation in HIV patients with abdominal symptoms.

7. True $(A)$ or false $(B)$ - click on the correct answer: Non-tuberculous mycobacterial infection is only seen in patients with well-preserved immunity.

8. True (A) or false (B) - click on the correct answer: Soluble transferrin receptor levels are low in patients with iron deficiency anaemia.

9. True $(A)$ or false $(B)$ - click on the correct answer: Transferrin levels are usually low in anaemia of chronic disorders.

10. True $(A)$ or false $(B)$ - click on the correct answer: Mycobacterium avium complex is a non-tuberculous mycobacterial infection that occurs most commonly in the duodenum in gastro-intestinal infections.
11. True $(A)$ or false $(B)$ - click on the correct answer: Pneumocystis jirovecii is an important protozoal opportunistic infection in HIV.

12. True (A) or false (B) - click on the correct answer: The Grocott-Gomori methamine-silver stain is useful for identifying non-tuberculous mycobacteria.

13. True (A) or false (B) - click on the correct answer: Treatment for $P$. jirovecii may involve atovaquone.

14. True (A) or false (B) - click on the correct answer: South Africa has a Traditional Health Practitioners Act (No. 22 of 2007) that requires registration by traditional healers.

15. True (A) or false (B) - click on the correct answer: In the study discussed in this journal, most traditional healers kept careful records of each of the treatment packages they prepared themselves.

16. True (A) or false (B) - click on the correct answer: A person engaging in potentially high-risk sexual activity as indicated on the South African National Blood Service questionnaire is deferred from blood donation for 6 months.

17. True (A) or false (B) - click on the correct answer: South Africa is a country where men who have sex with men may not donate blood.

18. True (A) or false (B) - click on the correct answer: Tablet returns may be a potential way of introducing adherence conversations with patients on ART.

19. True (A) or false (B) - click on the correct answer: A haemoglobin level below $8 \mathrm{~g} / \mathrm{dl}$ in an HIV-infected patient is probably due to anaemia of chronic disorders.

20. True $(A)$ or false $(B)$ - click on the correct answer: The Ziehl-Neelsen stain will show intracellular acid-fast bacilli in an M. avium complex infection. 


\section{SOUTHERN AFRICAN HIV CLINICIANS SOCIETY \\ APPLICATION / RENEWAL FORM \\ MEMBERSHIP FEES FOR 2010

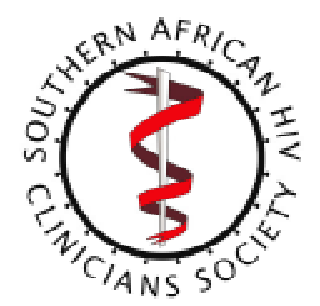

Annual Membership Fees: Private Sector R300 / Public Sector R150 / Associate Member R120

Renewal Fees are valid for 12 months from date of receipt of payment. Payments may be made by cheque or electronic transfer payable to: 'Southern African HIV Clinicians Society', Nedbank Campus Square, Branch code: 158-105

Account No: 1581048 033. Please fax proof of payment to the Database Manager on 0866822880

or post to: Suite 233, PostNet Killarney, Private Bag X2600, Houghton, 2041 Tel: + 27 (0) 113410162 E-mail:

sahivsoc@sahivsoc.org. Website: www.sahivsoc.org

NB! PLEASE PRINT LEGIBLY FOR ACCURATE ENTRY INTO THE DATABASE IN ORDER TO ENSURE RECEIPT OF SERVICES:

First name:

Surname:

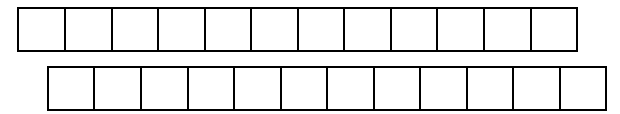

Initials:

Title:

Specialty:

Practice address

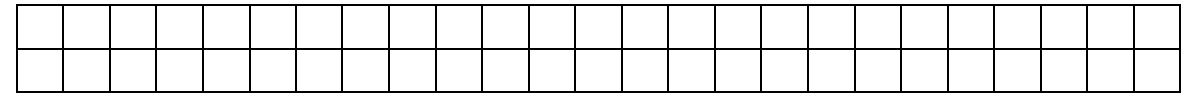

Postal Address:

City:

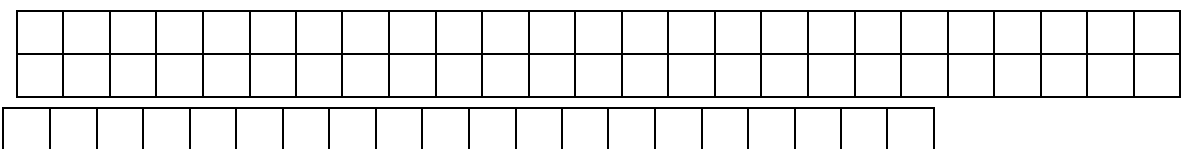

State/Province:

Country:

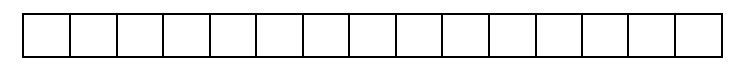

HPCSA.No:

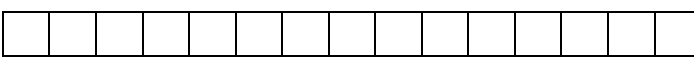

Postal Code:

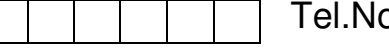

Fax:

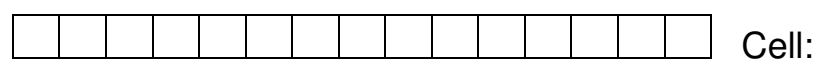

E-mail:

Please tick relevant box:

- Do you practice in the Private Sector

or in the Public Sector

$\square$ or Both

or Both

- Would you like your quarterly journal, the Southern African Journal of HIV Medicine, to be posted to you?

Would you like your quarterly journal, the Southern African Journal of HIV Medicine

- Preferred method for receiving your quarterly newsletter Transcript: E-mail

- $\quad$ Name(s) of HIV Training Courses successfully completed:.

Post

Method of payment: Electronic transfer:

Amount Paid:

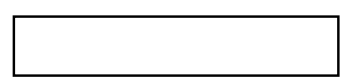

SOCIETY SERVICES:-

Quarterly issues of Southern African

Journal of HIV Medicine

Quarterly newsletter Transcript

CPD Points for: Branch Meetings,

Direct deposit:

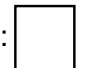

Post/Cheque:

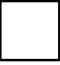

Cash:

Payment Date:

Journal questionnaires, published submissions

HIV/Aids CME: Courses/Alumni programme as training for Dip. HIV Med.Advocacy \& day-time telephonic consultancy
Conference information and discounts Regional and international representation Specialty sub-groups Local and International Guidelines 